\title{
Early Child Care Effects on Later Behavioral Outcomes Using a Canadian Nation-Wide Sample
}

\author{
Lyzon K. Babchishin ${ }^{1}$, Kelly Weegar ${ }^{1}$ \& Elisa Romano ${ }^{1}$ \\ ${ }^{1}$ School of Psychology, University of Ottawa, Ottawa, Canada \\ Correspondence: Lyzon K. Babchishin, School of Psychology, University of Ottawa, Ottawa, K1N 6N5, Canada.
}

Tel: 1-613-562-5800 Ext. 2265. E-mail: 1babc080@uottawa.ca

Received: May 13, 2013

doi:10.5539/jedp.v3n2p15
Accepted: May 29, 2013

Online Published: September 23, 2013

URL: http://dx.doi.org/10.5539/jedp.v3n2p15

\begin{abstract}
This study investigated the effects of child care type, quantity, and quality on later behavioral outcomes (e.g., hyperactivity-inattention, internalizing behavior). We used data from the Canadian National Longitudinal Survey of Children and Youth to examine child care characteristics for children 0-11 months who were using child care ( $N$ $=365$ ). Multiple regressions tested the impact of child care, while taking into account child and family variables, on behavioral outcomes at 6-7 years. Interactions between child care and family variables also were tested. Findings indicated that a regulated child care environment was associated with positive behavioral outcomes, even six years after the start of child care. Results also demonstrated that child care quality interacts with family variables to influence behavioral outcomes.
\end{abstract}

Keywords: child care, family, behavioral outcomes

\section{Introduction}

Participation in non-parental care prior to elementary school is a reality for many children (Bushnik, 2006; National Institute of Child Health and Human Development Early Child Care Research Network [NICHD ECCRN], 2005; Stein, et al., 2012). In fact, there has been a steadily growing demand for child care services in many industrialized countries since the mid 1970s, due in part to increases in the proportion of single-parent families with young children and in part to the number of women with children employed outside the home (Colin, 2007). Indeed, the rise in maternal employment has led to an increased use of non-parental child care in the early years, including infancy ( $<12$ months; Colin, 2007). The increase in the number of children receiving non-parental care has generated questions about the effects of early child care experiences on children's development. Findings have indicated that child care characteristics, such as quantity, type, and quality, impact children's behavioral outcomes (Belsky \& Pluess, 2011; Bradley \& Vandell, 2007; Geoffroy, Côté, Parent, \& Séguin, 2006; Melhuish, et al., 2006; NICHD ECCRN, 2002, 2001, 2005). However, discrepant findings on the effects of child care on child development are found in the literature, and this limited consensus is even more prominent for child care involvement in the first year of life (Burchinal \& Clarke-Stewart, 2007). The goal of the current study was to contribute to this growing literature on child care effects by conducting a longitudinal investigation within a Canadian context, and, furthermore, by focusing on children in child care during the first year of life.

\subsection{Child Care Characteristics}

Generally, the literature suggests that the amount of time spent in child care is positively associated with greater behavioral problems, including poor peer interactions, adjustment issues, less prosocial behavior, and more aggression (Belsky, 1986; Bradley \& Vandell, 2007; Fein \& Fox., 1988; NICHD ECCRN, 2006). Other researchers, however, have been unable to confirm the positive correlation between child care quantity and child behavior problems (McCartney et al., 2010; Romano, Kohen \& Findlay, 2010). It may be that the link between time spent in child care and behavioral outcomes is influenced by other aspects of child care (e.g., quality) as well as by individual and family characteristics. McCartney and colleagues (2010), for example, concluded that the number of hours spent in child care was more strongly related to externalizing behavior when children were in low-quality child care and when children spent a greater proportion of time with a large group of peers. As these associations are generally correlational, another explanation in terms of individual and family characteristics may be that parents with more difficult children place them in child care for a greater amount of time (McCartney, 2004). 
However, it should be noted that no empirical evidence exists for the role of child temperament on the selective use of child care.

Child care type has also been found to influence children's behavioral outcomes. Types of non-parental care arrangements typically include care in the child's home by a relative or non-relative, care in another individual's home by a relative or non-relative, and center-based care. In Canada, child care centers are licensed by a government body, and therefore all standards regulating adult-to-child ratios, group size, caregiver education, and the health and safety standards of the physical space typically are met (Romano et al., 2010). In comparison, regulation for home-based care may occur through a family daycare agency or a provincial/state ministry responsible for child care; however, this occurs on a voluntary basis and provincial/state licensing requirements often vary tremendously (National Association of Child Care Resource \& Referral Agencies, 2008; Romano et al., 2010). There are additional differences among child care types, with child care centers typically having the largest group sizes, the highest adult-to-child ratios, the most trained and educated caregivers, and the most stimulating environments in terms of structured and child-focused activities (Morrisey, 2010; Vandell, 2004). On the whole, greater exposure to center-based care has been related to child functioning in both positive and negative ways, predicting better language skills and memory performance (Bradley \& Vandell, 2007; NICHD ECCRN, 2006) as well as greater problem behaviors, such as teacher-reported externalizing problems from $4 \frac{1}{2}$ years through the end of sixth grade (Belsky et al., 2007). However, the effect of child care type is moderated by family and child characteristics, with different patterns of associations arising between types of child care for children from highand low-risk family backgrounds (Côté et al., 2008) and for age of entry (Lekhal, 2012). For example, some research has found that the negative effect of child care on the attainment of secure caregiver attachment is greater among infants compared to older children (Belsky, 2009).

Among the various child care characteristics, quality (e.g., positive interactions with caretakers and peers; high levels of cognitive and affective stimulation) appears to be most important (Baydar \& Brooks-Gunn, 1991; Bradley \& Vandell, 2007; Burchinal, Peisner-Feinberg, Bryant \& Clifford, 2000; NICHD ECCRN, 2006; Romano et al., 2010). Much information surrounding this topic stems from the National Institute of Child Health and Human Development (NICHD) Study of Early Child Care, which began in the early 1990s with the specific objective of examining child care effects over time in a sample of 1,364 0-3 year olds from various locations throughout the United States. Findings from the NICHD Study indicated that caregiver-reported behavior problems (e.g., distractibility, hostility) through the primary school years was related to child care quality, as assessed through the Observational Record of the Caregiving Environment (ORCE; NICHD ECCRN 2002; 2006). Likewise, the Effective Provision of Pre-school Education (EPPE), a prospective child care study of young children in the United Kingdom, found that higher child care quality (as assessed through the Early Childhood Environment Rating Scale-Revised; ECERS-R) predicted better child outcomes over the pre-school period, particularly greater social-behavioral development (Sammons et al., 2003). More recently, Maldonado-Carreño and Votruba-Drzal (2011) found that higher global quality of non-parental care (as measured by the ECERS-R and the Family Day Care Rating Scale) predicted improvements in teacher-reported academic skills and reductions in behavior problems in elementary school.

Recent Canadian data (Romano et al., 2010) further demonstrated that high-quality care (mother-reported) in home-based settings was significantly associated with behavioral outcomes (i.e., physical aggression and prosocial behavior) among a nationally representative sample of 4-5 year olds. Results also indicated several significant interactions between process quality (e.g., caregiver use of praise and activities that promoted language development) and household income for physical aggression and internalizing behavior, as well as between structure quality (e.g., safe environment) and parenting consistency for prosocial behavior. While this study relied on maternal reports of child care quality, the results were comparable to studies utilizing an observational method design (NICHD ECCRN, 2000).

\subsection{Child Care Quality and Moderating Factors}

The effects of child care quality do not work in isolation, but rather interact with other variables (e.g., individual factors, socio-demographics, parenting practices) in a number of potentially complex ways. For instance, when Sander and colleagues (1972) compared infants reared in group versus individual caretaking environments after birth, environmental differences (i.e., group-based vs. individual caregiver) as well as individual factors (e.g., age, sex) were significantly related to infant sleep/wake behavior (e.g., day/night differentiated sleep patterns). More recently, Romano et al. (2010) found family variables to be significantly associated with behavioral outcomes over and above the effects of child care and socio-demographic factors. In regards to socio-demographics, families with greater material and social resources (e.g., income, education, employment) appear more likely to use higher-quality child care and to attend center-based care, as child care (especially center-based care) is often a significant family 
expense (Burchinal \& Nelson, 2000). Bradley and Vandell (2007) noted that high-quality child care can serve as a protective factor for children at risk (e.g., children under the primary care of mothers exhibiting depressive symptoms). In concert, McCartney and colleagues (2007) suggested that child care quality can buffer the risks associated with low economic resources Specifically, they found that high-quality care was associated with better performance in school (e.g., school readiness) and improvements in the quality of the home environment (e.g., parent-child interactions, child cognitive stimulation), especially at the poverty level. While the mechanisms for the buffering effect of child care quality on school performance have been directly observed in child care environments (e.g., positive caregiving, stimulating environments), those behind improved home environments are not as clear. Some studies have proposed that the benefits of high-quality child care appear to reflect increased maternal knowledge and attitudes about childrearing (e.g., informal parent education during drop-off and pick-up, formal parenting education through workshops and study groups) as well as decreased parenting stress (Benasich, Brooks-Gunn \& Clewell, 1992). Nevertheless, the moderating effect of a family's social economic status (SES) on the relationship between child care and child outcomes has not been consistently replicated, with a number of studies finding only limited support for the moderating effect of SES (Burchinal et al., 2000).

The use of high-quality care has also been found to be associated with parents who provide more stimulating home environments, hold less authoritarian child-rearing beliefs, and use more responsive and sensitive practices (Burchinal \& Nelson, 2000; Lamb, 1998; NICHD ECCRN, 1999). As Burchinal and Nelson (2000) explain, research has clearly demonstrated that parents do not choose child care arrangements randomly. Consequently, research designed to delineate the effects of child care on children's developmental outcomes ought to account for such contextual factors. Nevertheless, while it is important to acknowledge parenting as a stronger and more consistent predictor of children's development than early child care experience, the quality of care still continues to significantly predict a variety of children's outcomes (Belsky et al., 2007).

\subsection{Long-Term Effects of Child Care}

Recent research has begun to examine the longer-term effects of child care on children's developmental outcomes. Based on data from the NICHD study, Vandell and colleagues (2010) examined the long-term impact of child care on children's behavioral and cognitive outcomes at age 15. In terms of behaviors, findings indicated that both quality and quantity of child care were linked with adolescent functioning. Specifically, high-quality early child care predicted less externalizing behavior, and increasing quantities of child care predicted greater risk taking and impulsivity at age 15. Risk taking behaviors were assessed using a computer-assisted self-interview, while impulsivity and externalizing behaviors were based on youth self-report questionnaires. Effects were similar in size to those observed at younger ages (i.e., preschool and school-age), and these effects remained statistically significant even after controlling for a variety of child, maternal, and family characteristics.

The findings from Vandell and colleagues (2010) are interesting because they counter arguments made that subsequent life experiences eventually override early child care experiences (Chin-Quee \& Scarr, 1994; Colwell, Pettit, Meece, Bates, \& Dodge, 2001). For example, Colwell and colleagues (2001) suggested that self-care (time child spent alone or with siblings) and unsupervised peer contact in the years following child care use are better indicators of children's externalizing problems in elementary school. To examine this hypothesis, these researchers examined the influence of continual non-parental care across four developmental periods (e.g., from infancy and preschool to Grade 6) to determine cumulative effects on the prediction of problematic behaviors. Using a longitudinal sample of 438 U.S. children, results indicated that neither infant nor preschool child care quantity was significantly associated with higher levels of elementary externalizing problems in Grade 6. Instead, Grade 1 self-care and Grade 6 unsupervised peer contact were modestly, but significantly, associated with increased teacher-rated externalizing behaviors in Grade 6. However, this study lacked information about the quality of non-parental care arrangements, which is most likely a more influential variable.

Recently, Stein and colleagues (2012) used data from the Families, Children, and Child Care (FCCC) study, a U.K. prospective longitudinal study of 1,201 children, to investigate early (i.e., infancy and toddlerhood) child care quantity, type and quality effects on behavioral and emotional development around the age of school entry. Specifically, hyperactivity, emotional problems, peer problems, contact disorder and prosocial behavior were assessed using sub-scales comprising the Strength and Difficulties Questionnaire, from which a total problem score was summed by combining all sub-scales except prosocial behavior. Findings suggested that children who spent more time in group care (mainly nursery care) from 0-51 months were more likely to have teacher- and mother-reported problems at school entry, specifically hyperactivity. In general, however, non-parental care had small effects on child outcomes at school entry, with the strongest and most consistent influences stemming from the home environment (e.g., quality of maternal care, socio-economic factors). The results also indicated that the quality of child care was not significantly related to later behavioral and emotional problems. 


\subsection{Study Objectives}

Generally speaking, knowledge pertaining to the long-term effects of child care is relatively limited and stems mostly from U.K.- and U.S.-based studies, despite substantial country-level variability in child care arrangements and related policies. For example, in Canada, progressive social policies (does not include the private sector) allow parents to stay home with infants up to 12 months (52 weeks) of age, compared to 40 weeks in the U.K. and 12 weeks in the U.S. (Alewell \& Pull, 2011). Moreover, while it is mandatory in Canada for all child care centers to be licensed by the provincial government, there is considerable inter-provincial variability about what the specific regulatory standards are and how these standards are enforced (Romano et al., 2010). In comparison, the U.S. government plays a more limited role in child care provision, relying mainly on giving parents subsidies to support their purchase of private child care, rather than offering places in publicly provided care; thus, the U.S. government has relatively little direct control over the type or quality of that care (Edie, 2006; Waldfogel, 2001). Likewise, child care in the U.K. is mostly private for children less than 3 years of age, with great variability in regulation across different parts of the country (Melhuish, et al., 2006).

This variability among countries suggests that existing research (primarily from the U.K. and U.S.) on long-term child care effects may not generalize to the Canadian context. As such, the goal of the current study was to examine the longer term effects of child care on children's behavioral outcomes using a nationally representative sample of Canadian children drawn from the National Longitudinal Survey of Children and Youth. We were particularly interested in potential effects associated with early child care $(<1$ year). This is because a dramatic rise in maternal employment has led to an increased use of non-parental child care in the early years, generally due to demands for both parents to return to work soon after birth (Colin, 2007; Stein et al, 2012). Furthermore, while there continues to be relatively limited consensus on the effects of child care involvement, the disparities in the literature are even greater for child care involvement in the first year of life (Burchinal \& Clarke-Stewart, 2007).

The lack of consensus, in particular with infancy care, suggests that different child care arrangements at different developmental periods may influence children's development in unique ways. In particular, infant care concerns tend to focus on secure attachment and the attainment of adequate stimulation necessary for infant emotional development, both of which can have long-term implications for behavioral and socio-emotional development (Jafee, Van Hulle, \& Rodgers, 2011). For example, stimulation levels and the maturation of sleep/wake cycles, which is particularly important in the first year of life, can, in turn, impact crying and smiling behaviors and the organization of behavioral states (Cecchini et al., 2012). Likewise, varying consistency in tacticle and communication processes (e.g., absent, continuous, discontinuous) can affect infants' crying behaviour and predispose them to interact differently with their environment (Cecchini, Lai, \& Langher, 2007). Therefore, research designed to delineate the effects of infant child care involvement on later functioning is valuable and has important implications in terms of child care policy. As such, we followed a cohort of children aged 0-11 months in child care (a within-child-care study) to examine the influence of child care characteristics (e.g., type, quantity, quality) on four specific behavioral outcomes at age 6, namely hyperactivity-inattention, physical aggression, internalizing and prosocial behavior. In examining child care effects, we also considered the potential impact of early child and family variables on later childhood behaviors, as well as interactions between child care quality, socio-demographic, and family variables. Our focus was on interactions involving child care quality because past research underscores quality child care as being influential in children's development. We hypothesized that a more favorable child care setting (e.g., higher quality) and family environment (e.g., positive parenting practices, less maternal depression) would be associated with fewer negative and greater positive behavioral outcomes. We also expected child care quality to moderate the associations of socio-demographic and family variables on later behavioral outcomes.

\section{Method}

\subsection{Participants}

The National Longitudinal Survey of Children and Youth (NLSCY), a Canadian population-based survey of children that began in 1994, provides a rich source of information on diverse childhood experiences (including child care), family circumstances, and child behavior outcomes. Households were selected from Statistics Canada's Labor Force Survey, which uses a stratified multistage probability sample design and is representative of Canada's population. However, it excludes children living in institutional facilities, on Aboriginal reserves, and in the Canadian territories (approximately $0.5 \%$ of $0-11$ year olds). The primary data collection measure is a biennial computer-assisted personal home interview with the individual most knowledgeable about the child, which in approximately 90\% of cases is the child's biological mother (Statistics Canada and Human Resources Development Canada, 1995). Participants for the current study included children 0-11 months at cycle 4 
(2000-2001) who were currently in a non-parental child care setting. We relied on data from cycle 4 because it is the first cycle to include information on child care quality in various types of settings. Data on behavioral outcomes were collected at cycle 7 (2006-2007) when children were 6-7 years of age. Table 1 presents socio-demographic characteristics for the 365 0-11 month olds in non-parental child care and compares them to children $(n=506)$ who were excluded from the study as they were in exclusive parental care. There were statistically significant differences in child age and ethnicity, maternal education and employment, and household income.

Table 1. Sample description for 0-11 month old children in NLSCYcycle 4

\begin{tabular}{|c|c|c|c|c|c|c|c|c|}
\hline & \multicolumn{3}{|c|}{$\begin{array}{l}\text { In Child Care } \\
(n=365)\end{array}$} & \multicolumn{3}{|c|}{$\begin{array}{l}\text { Not In Child Care } \\
(n=506)\end{array}$} & \multicolumn{2}{|l|}{ Statistics } \\
\hline & $M$ & $S D$ & $\%$ & $M$ & $S D$ & $\%$ & $t$ & $\chi^{2}$ \\
\hline \multicolumn{9}{|l|}{$\underline{\text { Child Variables }}$} \\
\hline Age (Months) & 8.7 & 1.8 & & 7.3 & 2.6 & & $-8.37 * * *$ & \\
\hline \multicolumn{9}{|l|}{ Sex } \\
\hline Female & & & 48.2 & & & 46.8 & & 0.15 \\
\hline Male & & & 51.8 & & & 53.2 & & \\
\hline \multicolumn{9}{|l|}{ Ethnicity } \\
\hline Majority (Caucasian) & & & 84.2 & & & 76.5 & & $7.45^{* *}$ \\
\hline Minority (Other) & & & 15.8 & & & 23.5 & & \\
\hline \multicolumn{9}{|l|}{ Family Variables } \\
\hline \multicolumn{9}{|l|}{ Maternal Employment } \\
\hline No in last 12 months & & & 10.7 & & & 43.8 & & $103.84 * * *$ \\
\hline Yes in last 12 months & & & 89.3 & & & 56.2 & & \\
\hline \multicolumn{9}{|l|}{ Maternal Education } \\
\hline Less than high school & & & 11.7 & & & 17.8 & & $19.26^{* * *}$ \\
\hline High school & & & 30.8 & & & 40.8 & & \\
\hline College/University & & & 57.5 & & & 42.1 & & \\
\hline \multicolumn{9}{|l|}{ Family Structure } \\
\hline Single parent & & & 7.5 & & & 6.3 & & 0.39 \\
\hline Two parents & & & 92.5 & & & 93.7 & & \\
\hline \multicolumn{9}{|l|}{ Household Income } \\
\hline $\mathrm{LICO}>1.25$ & & & 87.9 & & & 93.6 & & $7.13 * *$ \\
\hline $\mathrm{LICO} \leq 1.25$ & & & 12.1 & & & 6.4 & & \\
\hline
\end{tabular}

Notes. $M=$ mean; $S D=$ Standard deviation; $\%=$ Percentages; $X^{2}=$ Chi square.

$* p<.05 * * p<.01 * * * p<.001$

\subsection{Child Care Predictors}

For regulatory status, all child care centers in Canada are licensed by their respective provincial government and therefore meet regulatory standards (i.e., adult-to-child ratios, group size, caregiver education; Romano et al., 2010). Care in the child's own home (by a relative or non-relative) and care outside the child's home (by a relative or 
non-relative) are not required to be regulated. For these home-based settings, mothers reported whether or not the child care provider was licensed by the provincial government or approved by a family daycare agency (Statistics Canada, 2003). In other words, regulated care consisted of child care centers and some home-based settings, while unregulated care consisted of care in children's own home or home-based care outside of their home by a relative or non-relative. Quantity of time spent in non-parental arrangements was measured with one item (i.e., How many hours per week does the child typically spend in child care?) connected to the child's main type of care arrangement. While the child care quantity variable was originally continuous, it was categorized to rectify problematic skew (i.e., $<10$ hours, 10-19, 20-29, 30-39, > 40). Child care type was determined through one item (i.e., What is your child's care arrangement?), and response categories included (a) care in someone else's home by a non-relative, (b) care in someone else's home by relative, (c) care in child's home by non-relative, (d) care in child's home by relative, and (e) daycare center (Statistics Canada, 2008). For purposes of this study, child care type was dichotomized into homeand center-based care.

Child care quality was defined by both structure and process variables. Process variables included responses to the following three items along a 4-point scale (never, rarely, sometimes, often): (a) How often would you say your caregiver praises and encourages your child and responds promptly when he/she needs help or comforting?; (b) How often does your caregiver plan activities and use toys and other materials to help your child learn new things?; and (c) How often does your caregiver encourage your child's language development by talking to him/her and asking questions, as well as using songs and stories for this purpose? These variables were summed to create a continuous process quality variable $(\alpha=.72)$, where high scores indicated high process quality. Mothers also responded to two items on structure quality, specifically: (a) In this arrangement, does your child have a clean, safe area to play in - both indoors and outdoors? (response categories: no - not at all, no - not very often, yes sometimes, yes - all the time) and (b) To your knowledge, does this relative have any training in early childhood education, or child care, at the college or university level" (response categories: yes, no). These variables were summed to compute an overall continuous structure quality variable $(\alpha=40)$, where high scores indicated high structure quality.

\subsection{Family and Child Covariates}

In cycle 4 (2000-2001), socio-demographic information was gathered on parental education and employment as well as on family structure (i.e., intact two-parent family or non-intact families including single parent and stepfamily households) and household income. The latter was based on Statistic Canada's low income cut-off (LICO), which estimates the minimum household income needed to meet basic needs (e.g., food, shelter), with different cut-offs based on family size and community of residence (Statistics Canada, 2003). Parenting practices were examined using the Parent Practices Scale (Strayhorn \& Weidman, 1988), with mothers responding to items along a 5-point scale from "Never" (0) to "Many times each day or always" (4). There were five positive interaction items (e.g., How often do you praise your child by saying something like 'Good for you' or 'What a nice thing you did' or 'hat's good going!'?; $\alpha=.60)$. Parenting ineffectiveness $(n=2)$ was also investigated (e.g., How often do you get annoyed with your child for doing something he/she is not supposed to?; $\alpha=.34$ ). For both positive interaction and family ineffectiveness, each item was rated along a 4-point scale from "Rarely or none of the time ( $<1$ day)" ( 0 ) to "Most or all of the time (5-7 days)" (3). To examine family functioning, 13 items from the McMaster Family Assessment Device (Byles, Byrne, Boyle, \& Offord, 1988) were used, each of which was rated along a 4-point scale from "Strongly agree" (0) to "Strongly disagree" (3; e.g., We express feelings to each other; $\alpha$ $=.89$ ).

In addition, mothers completed a child temperament scale based on the Infant Characteristic Questionnaire (Bates, Freeland \& Lounsbury, 1979). There were 19 items (e.g., How easy is it for you to know what s bothering him/her when he/she cries or fusses?) that were rated on a 7-point scale, ranging from 1 (more favorable response) to 7 (more unfavorable or difficult response). Finally, a child care control variable was created by combining mother reports of child care use (yes or no) in cycles 5 and 6.

\subsection{Behavioral Outcomes}

The measure used to assess children's behavioral outcomes in cycles 7 was drawn from a Canadian adaptation of the Child Behavior Checklist (Achenbach \& Edelbrock, 1981) and factor analyzed by methodologists at Statistics Canada to yield behavior subscales. These included mother-reported hyperactivity-inattention ( 7 items; e.g., Cannot sit still or is restless; $\alpha=.78$ ), physical aggression ( 6 items; e.g., Gets into many fights; $\alpha=.72$ ), internalizing behavior ( 7 items; e.g., Seems to be unhappy or sad; $\alpha=.70$ ) and prosocial behavior (10 items; e.g., Volunteers to help clean a mess that someone else has made; $\alpha=80$ ). Items were rated along a 3-point scale from "Never or not true" $(0)$ to "Often or very true" (3; Statistics Canada, 2008). 


\subsection{Data Analyses}

Hierarchical regressions were conducted for each behavioral outcome and included five child care predictors (regulated care, quantity, structure quality, process quality, and type), two child covariates (sex and temperament), and five family covariates (hostile/ineffective parenting, positive parenting, family functioning, family structure, household income). Preliminary analyses to verify statistical assumptions for multiple regressions revealed that the process quality variable was significantly skewed. As such, a square root transformation was completed. Further, with the exception of regulated and center-based care which were strongly correlated (albeit not excessive), correlations between all predictor variables did not suggest any difficulty with multicollinearity, as reported in Appendix A. The strong correlation between regulatory status and center-based care is not surprising, given that all centers in Canada are required to be licensed and, therefore, meet regulatory standards. The interactions between process and structure quality of child care and family functioning and household income on behavioral outcomes were also considered, from which significant interactions were plotted in order to determine directionality (as recommended by Aiken and West, 1991). Missing data was low (range 0.8-4.1\%), and variable with the most missing data was family dysfunction (4.1\%). We used the fully conditional Markov Chain Monte Carlo (MCMC) method to impute missing data for all variables. The MCMC method can handle categorical variables as well as arbitrary missing data patterns. It assumes an iterative approach that fits a single variable using all other variables in the model as predictors and then imputes missing data for the single variable being fit.

The method continues for each variable in the model to the maximum number of iterations specified, which was 10 in the current study. We also applied NLSCY longitudinal weights to the regression analyses to account for the complex survey design. A probability level of .05 was used to establish statistical significance.

\section{Results}

\subsection{Descriptive Analyses}

Table 2 presents descriptive data on outcome and predictor variables for our sample. There was some variability in mean scores across the different behavioral outcomes. Scores tended to fall on the low to middle range of the scale, which is not surprising given that the children were drawn from a community-based population. For the child care variables, 1 in 4 children (26.8\%) was in a regulated child care setting, which included child care centers (43.5\%), care in someone else's home by a non-relative $(39 \%)$ or a relative $(1.5 \%)$, care in own home (i.e., by relative or non-relative; $16.1 \%)$. The majority of $0-11$ month olds $(73.2 \%)$, however, were in home-based child care settings that primarily were not regulated. For children in home-based settings, the breakdown was as follows: $55.1 \%$ were cared for by a relative either in the child's own home or in the relative's home; $31.5 \%$ were cared for in someone else's home by a non-relative; and $13.4 \%$ were cared for by a non-relative in the child's own home. Across all child care arrangements, 4 in 10 children (41.8\%) were using child care for more than 30 hours per week and process and structure quality scores were moderately high (means of 11.67 and 5.17 respectively). Table 2 presents further data on family and child variables.

Table 2. Outcome and predictor variables for 0-11 month olds in child care $(\mathrm{N}=365)$

\begin{tabular}{|c|c|c|c|c|}
\hline & $M$ & $S D$ & Range & $\%$ \\
\hline \multicolumn{5}{|l|}{ Outcome Variables } \\
\hline Hyperactivity-inattention & 11.64 & 2.94 & $0-21$ & \\
\hline Physical aggression & 7.51 & 1.86 & $0-18$ & \\
\hline Internalizing behavior & 9.71 & 2.21 & $0-21$ & \\
\hline Prosocial behavior & 24.18 & 3.52 & $0-30$ & \\
\hline \multicolumn{5}{|l|}{ Predictor Variables } \\
\hline \multicolumn{5}{|l|}{ Child Care } \\
\hline Process quality & 11.67 & 0.83 & $0-16$ & \\
\hline Structure quality & 5.17 & 0.48 & $0-8$ & \\
\hline \multicolumn{5}{|l|}{ Hours in care (per week) } \\
\hline Less than 10 & & & & 17.4 \\
\hline $10-19$ & & & & 20.1 \\
\hline $20-29$ & & & & 20.7 \\
\hline $30-39$ & & & & 14.3 \\
\hline $40+$ & & & & 27.5 \\
\hline
\end{tabular}




\begin{tabular}{|c|c|c|c|c|}
\hline Regulated care & & & & 26.8 \\
\hline Center-based care & & & & 11.7 \\
\hline \multicolumn{5}{|l|}{ Child } \\
\hline \multicolumn{5}{|l|}{ Gender } \\
\hline Male & & & & 51.7 \\
\hline Female & & & & 48.3 \\
\hline Temperament & 35.59 & 10.27 & $19-133$ & \\
\hline \multicolumn{5}{|l|}{ Family } \\
\hline Hostile/ineffective interactions & 1.42 & 1.73 & $0-8$ & \\
\hline Positive interactions & 17.90 & 2.22 & $0-20$ & \\
\hline Family dysfunction & 8.62 & 4.86 & $0-24$ & \\
\hline \multicolumn{5}{|l|}{ Family composition } \\
\hline Intact family & & & & 88.1 \\
\hline Other & & & & 11.9 \\
\hline Household income (LICO) & 2.73 & 0.57 & $1-6$ & \\
\hline
\end{tabular}

Note. $M=$ mean; $S D=$ standard deviation; $\%$ = percentage; data are imputed and weighted.

\subsection{Predictors of Child Behavioral Outcome}

When children were 6-7 years (see Table 3), results indicated that having been in a regulated child care setting during the first year of life predicted fewer behavioral problems, specifically less mother-reported hyperactivity-inattention. However, children 0-11 months who were in center-based care had significantly higher levels of hyperactivity-inattention at 6-7 years of age. There were no other significant associations between child or child care variables and behavioral outcomes. In terms of parenting, higher levels of hostile/ineffective interactions at 0-11 months were significantly associated with higher levels of hyperactivity-inattention at 6-7 years. Conversely, lower levels of hostility/ineffectiveness during the first year of life, as well as greater household income as indicated by the LICO score, predicted higher mother-reported prosocial behavior at 6-7 years. There were no other significant family variables for the remaining behavioral outcomes.

Table 3. Child care, child and family predictors of childhood behavior outcomes for children in child care

\begin{tabular}{|c|c|c|c|c|c|c|c|c|}
\hline & \multicolumn{2}{|c|}{$\begin{array}{l}\text { Hyperactivity-Inatt } \\
\text { ention }\end{array}$} & \multicolumn{2}{|c|}{$\begin{array}{l}\text { Physical } \\
\text { Aggression }\end{array}$} & \multicolumn{2}{|c|}{$\begin{array}{l}\text { Internalizing } \\
\text { Behavior }\end{array}$} & \multicolumn{2}{|c|}{$\underline{\text { Prosocial }}$} \\
\hline & $\bar{B}$ & $S E$ & $B$ & $\overline{S E}$ & $\bar{B}$ & $S E$ & $B$ & $S E$ \\
\hline \multicolumn{9}{|l|}{ Child Care } \\
\hline Process quality & -.13 & .30 & -.13 & 20 & -.20 & .23 & -.22 & .39 \\
\hline Structure quality & 41 & .33 & .00 & .21 & .12 & .25 & -.41 & .43 \\
\hline Regulated care & $-1.36^{* *}$ & .46 & .56 & .30 & -.51 & .35 & -1.03 & .60 \\
\hline Center-based care & $1.98^{* *}$ & .63 & .27 & .40 & .83 & .47 & .84 & .81 \\
\hline Quantity of care & .05 & .11 & -.07 & .07 & -.00 & .08 & -.24 & .14 \\
\hline \multicolumn{9}{|l|}{ Child } \\
\hline Female child & -.49 & .31 & .33 & 20 & 22 & .24 & -.19 & .40 \\
\hline Temperament & .18 & 19 & -.00 & .12 & -.18 & .15 & -.35 & .24 \\
\hline \multicolumn{9}{|l|}{ Family } \\
\hline $\begin{array}{l}\text { Hostile/ineffective } \\
\text { parenting }\end{array}$ & $.25^{*}$ & .10 & .07 & .06 & .12 & .07 & $-.24^{*}$ & .12 \\
\hline Positive interactions & -.02 & .07 & -.08 & .05 & -.05 & .06 & .06 & .09 \\
\hline Family dysfunction & .02 & .03 & .00 & .02 & -.03 & .03 & .01 & .04 \\
\hline Intact family structure & -.65 & .50 & -.19 & .32 & -.11 & .39 & .16 & .63 \\
\hline $\begin{array}{l}\text { Household income } \\
\text { (LICO) }\end{array}$ & -.06 & .28 & -.04 & .18 & -.29 & .22 & $.86^{*}$ & .38 \\
\hline Overall $\mathrm{R}^{2}$ & $.29 * *$ & & .22 & & .20 & & $.26^{*}$ & \\
\hline
\end{tabular}

Note. $B=$ Unstandardized beta; $S E=$ Standard error; ${ }^{*} p<.05 ; * * p<.01 ; * * * p<.001$ 


\subsection{Moderating Effects}

Interaction results suggested that the family environment, in particular family dysfunction and household income (LICO), significantly interacted with child care quality during the first year of life to determine later behavioral outcomes. In particular, children in families high on family dysfunction displayed more hyperactivity-inattention in low process quality child care arrangements; however, when process quality was high, their hyperactivity-inattention scores decreased (see Figure $1 ; \beta=3.71 ; p<.001)$. As indicated in Figure $2(\beta=2.54 ; p$ $<.001$ ), children from low income households exhibited more hyperactivity-inattention in low structure quality arrangements, whereas hyperactivity-inattention behaviors decreased when these children were in a high structure quality child care arrangement. Finally, Figure $3(\beta=2.69 ; p<.001)$ indicates that children in low income households displayed more internalizing behaviors if they were in a child care setting that was low on process quality, but these behaviors decreased with the introduction of high process quality care.

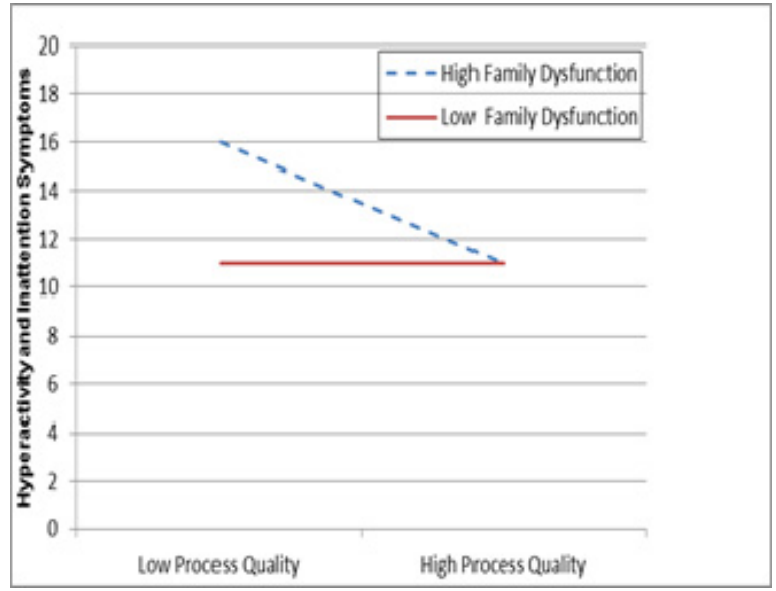

Figure 1. The interaction between family dysfunction and process quality on hyperactivity and inattention.

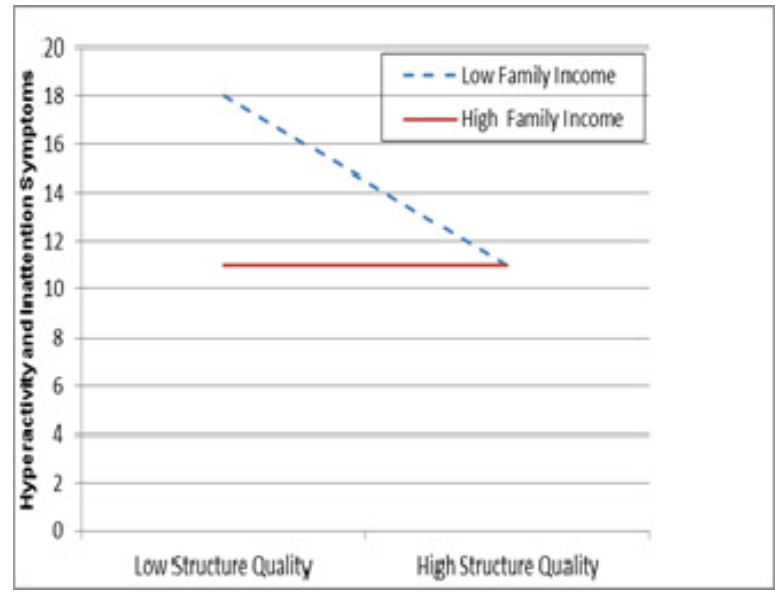

Figure 2. The interaction between family income and structure quality on hyperactivity and inattention.

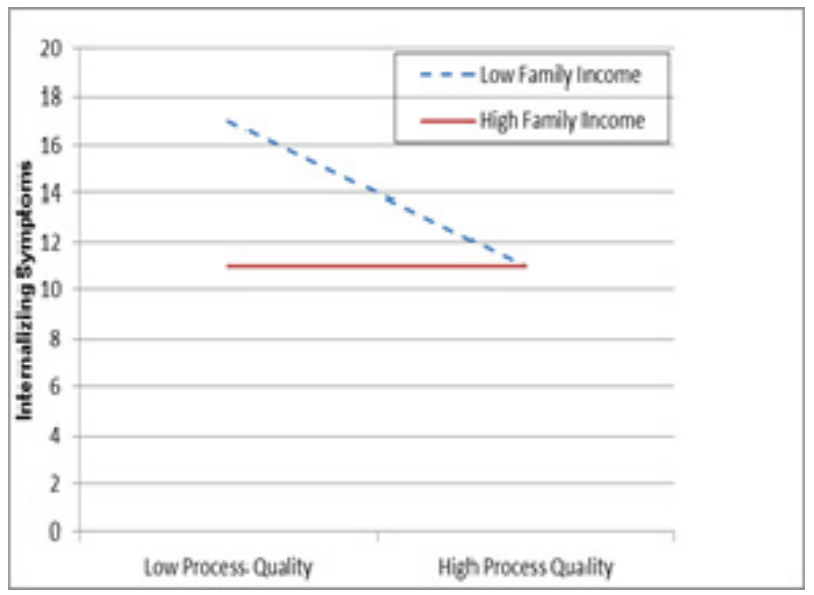

Figure 3. The interaction between family income and process quality on internalizing behavior.

\section{Discussion}

Even after taking into account a number of child and family factors, results from the current study indicate that child care during the first year of life continued to influence children's behavioral outcomes at 6-7 years of age. At this age, we found that early child care characteristics, specifically regulated care and center-based care, were significantly associated with hyperactivity-inattention. As hypothesized, children in non-regulated child care displayed greater hyperactive-inattentive behavior, which is of concern as approximately three-quarters of children in our sample were in a non-regulated child care setting. Regulatory status was also a stronger predictor 
of behavioral outcomes at 6-7 years than process and structure quality. It may be that regulated care is a more objective measure of child care quality, compared to mother-reported responses about child-caregiver interactions and child care environment, which may be sensitive to reporter bias. Indeed, the association of non-regulated care with poor behavioral outcomes is consistent with past research findings using both cross-sectional (e.g., physical aggression; Romano et al., 2010) and longitudinal (e.g., risk-taking and impulsivity; Vandell et al., 2010) methodology.

The association between center-based care and increased hyperactivity-inattention at 6-7 years was unexpected given that all centers are required to be regulated in Canada. It is difficult to compare our findings to past research which has relied primarily on samples of U.S. and U.K. children because of the differences in child care policies. Nevertheless, findings from a U.K.-based prospective longitudinal study of 1,201 children (FCCC study) also suggested that children who spent more time in group care from 0-18 months were more likely to have behavioral problems, specifically hyperactivity (Stein et al., 2012). Furthermore, while Stein and colleagues (2012) examined a range of behavioral outcomes, such as emotional problems, peer problems, contact disorder, and prosocial behavior, their results also indicated that child care effects were only present for hyperactivity and none of the other behaviors measured, lending additional support to the results for the current study.

Our study also found that the number of hours spent in child care in infancy was not a significant predictor of later behavioral outcomes. While previous research has demonstrated that increased child care quantity can be associated with behavioral problems, this is not a conclusive finding (McCartney et al., 2010; Romano, Kohen \& Findlay, 2010). Furthermore, McCartney and colleagues (2010) explain that the number of hours spent in child care has been more strongly related to behavioral problems when children spend a greater proportion of time with a large group of peers. Since our study focused only on infants (aged 0-11 months), it is likely that our sample experienced relatively limited peer interactions. In addition, while there was variability in the number of hours spent in care, the majority of infants in our sample experienced home-based child care, wherein small numbers of children and low adult-to-infant ratios are typical. Therefore, peer interactions would be relatively minimal in these settings.

As anticipated, family variables also predicted behavioral outcomes over and above the effects of child care. Particularly, greater hyperactivity-inattention was found in children who experienced more hostile/ineffective interactions as infants, whereas prosocial behavior was found in children coming from households with greater incomes and less parental hostility/ineffectiveness. These results are consistent with past research (Bradley \& Vandell, 2007; Romano et al., 2011) and underscore the unyielding importance of parenting practices and other family factors on children's behavioral outcomes. On the other hand, there were no family predictors for later physical aggression and internalizing behavior, contrary to other findings in the literature (e.g., NICHD ECCRN 2003, Romano et al., 2011). The low internal reliability and range for physical aggression and internalizing behavior observed in our sample could obscure significant results, even though restricted range is expected in community compared to clinical samples. Indeed, there is growing evidence that high levels of internalizing behavior (e.g., negative emotionality) and physical aggression during infancy and toddlerhood are both predictive of chronic externalizing and internalizing behavior problems (Gartstein et al., 2012; Tremblay et al., 2004).

Interaction results suggest that the family environment is particularly important when examining the effects of infant child care. We found that children in higher risk families (i.e., low income and high family dysfunction) seem to especially benefit from high quality care. This finding is consistent with past findings that higher quality care may serve as a protective factor for at-risk children (Love et al., 2003; McCartney et al., 2003; Votruba-Drzal et al., 2010). As Votruba-Drzal and colleagues (2010) explain, low-income children, faced with limited resources in their home environments, may be especially responsive to the added supports of stimulating and responsive non-parental care or, conversely, the added risks of poor quality child care. In particular, as infancy represents a period of significant brain development, high quality care within this period may serve as a particularly salient protective factor for at-risk children.

Knowledge pertaining to the long-term effects of child care in Canada is relatively limited. Consequently, findings from this study may differ as Canadian child care policies and regulatory standards vary greatly from policies and standards in other countries, thus offering valuable knowledge regarding experiences that may be unique to Canadian child care settings. The current study also adds valuable findings regarding child care experiences that may be unique to infancy, since a lot of past research has tended to focus on the impact of attending child care in the preschool years rather than during infancy alone. Indeed, some researchers suggest that there are unique outcomes for children who begin care early in life, such as increased risk for negative behaviors (Baydar \& Brooks-Gunn, 1991; Bradley \& Vandell, 2007) and higher levels of emotional issues (Côté et al., 2008), as these children may be more likely to experience disruptions (e.g., regular parental absence). Morrisey (2010) alternatively suggests that child care type should correspond with children's developmental needs as they age. For 
example, the small number of children and low adult-to-infant ratios characteristic of home-based care may allow for more individual adult-child time for infants and toddlers, whereas the social stimulation found in center-based care during the preschool years may prepare children for kindergarten.

\subsection{Limitations}

It is important to note several limitations in our study. First, while we included a number of variables in the analyses, undoubtedly additional variables might have influenced children's behavioral outcomes. For example, we were unable to assess child care quality over time because several of the items used in the NLSCY were not consistent from cycle to cycle. Indeed, as the current study was designed to evaluate the effects of early child care exposure, we did not exclude participants that were not in care after cycle 4 (e.g., 15.9\% in cycle 5). As such, a portion of our sample may not have been exposed to care for long enough to determine the long-term impact of child care. Second, the study relied exclusively on parent-reported measures. Some researchers claim that parents are not accurate reporters of child care quality in that there are significant inconsistencies between parents and trained observers on such measures (Burchinal \& Nelson, 2000). This is understandable given that parents are generally not present for significant lengths of time during the child care day. Nonetheless, Burchinal and Nelson (2000) noted that even observations by trained data collectors of child care quality over several periods of time most likely cannot entirely describe the child care experiences of the child. Parents also likely want to be reassured that their children are in safe, good-quality child care and so parental reports may over-estimate the quality of their child's non-parental care (Romano et al., 2010). Despite these limitations, researchers have found that parental reports can provide reliable information on various aspects of child care (Baydar \& Brooks-Gunn, 1991; Rosenthal \& Vandell, 1996). It should also be noted that in large scale nationally-representative surveys such as the NLSCY, parental reports may be the only viable option. Despite our reliance on parental reports, our findings were consistent with past studies that have used observational assessments of child care quality (e.g., Vandell et al., 2010), suggesting that parental reports represent an important source of information.

\subsection{Implications}

The present study contributed to our growing understanding of long-term child care effects in several ways. First, data were drawn from a nationally-representative sample of Canadian children, thereby increasing the generalizability of our findings, as well as offering valuable knowledge regarding experiences that may be unique to Canadian child care settings. Second, past research on the long-term influence of child care has tended to use broad behavioral categories such as internalizing and externalizing behaviors (e.g., Côté et al., 2008; NICHD ECCRN, 2005) or has investigated externalizing behaviors exclusively (e.g., McCartney et al., 2010; Votruba-Drzal et al., 2010). Our focus on more specific behaviors allowed us to make finer distinctions regarding the ways in which child care might differentially impact specific child behavioral outcomes. In addition, the bulk of the current literature examines the effects of child care in preschool or school-aged children (NICHD ECCRN, 2005).

Comparatively, due to the current need for research on the effects of child care in infancy (Jafee, Van Hulle, \& Rodgers, 2011), this study has been designed to evaluate the effects of child care placement in infancy (0 to 11 months) on outcomes in the school-age period (6-7 years). Additionally, the current study used a robust model to examine the impact of early child care experiences on later behavioral outcomes, as it controlled for a number of family influences and child care experiences using a nationally representative sample of Canadian children. Our findings that several child care characteristics remained significant on a longer-term basis suggest that child care continues to influence children's behavioral outcomes years after their participation in child care, even for children enrolled in their first year of life. The results regarding the impact of regulated child care are of particular importance for parents, child care providers, and policy makers. In particular, regulated care needs to be prioritized in early child care program planning in order to ensure greater accessibility to high quality care. Our findings also suggest that unique characteristics of different child care arrangements may be suited to promote development at different developmental stages, although more research is needed to explore this further. Future research should also address additional childhood outcomes such as cognitive functioning and measures of preschool outcomes as assessed by various raters other than parents. Given the dynamic interplay between child care and contextual factors, it remains important to examine and consequently disseminate the nature of these influences to ensure that maximal benefits are attained for all children.

\section{References}

Achenbach, T. M., \& Edelbrock, C. S. (1981). Behavioral problems and competencies reported by parents of normal and disturbed children aged four through sixteen. Monographs for the Society for Research in Child Development, 46 (1, Serial No. 188). http://dx.doi.org/10.1177/02711214030230040201

Aiken, L. S., \& West, S. G. (1991). Multiple regression: Testing and interpreting interactions. London: Sage. 
Alewell, D., \& Pull, K. (2011). The international regulation of maternity leave: Leave duration, predictability, and employer-co-financed maternity pay. International Business \& Economic Research Journal, 1, 45-59. Retrieved from http://journals.cluteonline.com/index.php/IBER/article/view/3893/3937

Bates, J. E., Freeland, C. A., \& Lounsbury, M. L. (1979). Measurement of infant difficultness. Child Development, 50, 794-803. http://dx.doi.org/10.2307/1128946

Baydar, N., \& Brooks-Gunn, J. (1991). Effects of maternal employment and child-care arrangements on preschoolers' cognitive and behavioral outcomes: Evidence from the children of the National Longitudinal Survey of Youth. Developmental Psychology, 27, 932-945. http://dx.doi.org/10.1037/0012-1649.27.6.932

Belsky, J. (2009). Early Day-Care and Infant-Mother Attachment Security. Encyclopedia on Early Development. P1-5. Available online at http://www.child-encyclopedia.com/documents/BelskyANGxp-Child_care2.pdf

Belsky, J., Burchinal, M., McCartney, K., Vandell, D. L., Clarke-Stewart, K. A., \& Owen, M. T. (2007). Are there long-term effects of early child care? Child Development, 78, 681-701. http://dx.doi.org/10.1111/j.1467-8624.2007.01021.x

Belsky, J., \& Pluess, M. (2011). Differential susceptibility to long-term effects of quality child care on externalizing behaviour in adolescence? International Journal of Behavioral Development, 36, 2-10. http://dx.doi.org/10.1177/0165025411406855

Benasich, A. A., Brooks-Gunn, J., \& Clewell, B. C. (1992). How do mothers benefit from early intervention programs? Journal of Applied Developmental Psychology, 13, 311-362. http://dx.doi.org/10.1016/0193-3973(92)90035-G

Bradley, R. H., \& Vandell, D. L. (2007). Child care and the well-being of children. Archives of Pediatric and Adolescent Medicine, 161, 669-676. http://dx.doi.org/10.1001/archpedi.161.7.669.

Bushnik, T. (2006). Child care in Canada. Ottawa, ON, Canada: Special Surveys Statistics Canada. Retrieved from http://publications.gc.ca/Collection/Statcan/89-599-MIE/89-599-MIE2006003.pdf

Burchinal, M. R., \& Clarke-Stewart, K. A. (2007). Maternal employment and child cognitive outcomes: The importance of analytic approach. Developmental Psychology, 43, 1140-1155. http://dx.doi.org/10.1037/0012-1649.43.5.1140

Burchinal, M. R., Peisner-Feinberg, E., Bryant, D. M., \& Clifford, R. (2000). Children's social and cognitive development and child care quality: Testing for differential associations related to poverty, gender, or ethnicity. Applied Developmental Science, 4, 149-165. http://dx.doi.org/10.1207/S1532480XADS0403_4

Burchinal, M. R., \& Nelson, L. (2000). Family selection and child care experiences: Implications for studies of child outcomes. Early Childhood Research Quarterly, 15, 385-411. http://dx.doi.org/10.1016/S0885-2006(00)00072-7

Byles, J., Byrne, C., Boyle, M. H., \& Offord, D. R. (1988). Ontario Child Health Study: Reliability and validity of the General Functioning subscale of the McMaster Family Assessment Device. Family Process, 27, 97-104. http://dx.doi.org/10.1111/j.1752-0606.1985.tb00028.x

Cecchini, M., Baroni, E., Di Vito, C., Piccolo, F., Aceto, P., \& Lai, C. (2012). Effects of different types of contingent tactile stimulation on crying, smiling, and sleep in newborns: An observational study. Developmental Psychobiology. http://dx.doi.org/10.1002/dev.21054

Cecchini, M., Lai, C., \& Langher, V. (2007). Communication and crying in newborns. Infant Behavior \& Development, 30, 655-665. http://dx.doi.org /10.1016/j.infbeh.2007.03.002

Chin-Quee, D. S., \& Scarr, S. (1994). Lack of early child care effects on school-age children's social competence and academic achievement. Early Development and Parenting, 3(2), 103-112. http://dx.doi.org/10.1002/edp.2430030207

Colin, L. (2007). Census snapshot on Canada: Families. Canadian Social Trends, 84, 39-40. Retrieved from http://www.statcan.gc.ca/pub/11-008-x/2007006/article/10380-eng.pdf

Colwell, M., Pettit, G., Meece, D., Bates, J. E., \& Dodge, K. A. (2001). Cumulative risk and continuity in nonparental care from infancy to early adolescence. Merrill-Palmer Quarterly, 47, 207-234. http://dx.doi.org/10.1353/mpq.2001.0009

Coplan, R., Findlay, L. C., \& Schneider, B. H. (2010). Where do "anxious" children fit best? Childcare and the emergence of anxiety in early childhood. Canadian Journal of Behavioral Science, 42, 185-193. 
http://dx.doi.org/10.1037/a0019280

Côté, S. M., Borge, A. I., Geoffroy, M-C., Rutter, M., \& Tremblay, R. E. (2008). Nonmaternal care in infancy and emotional/behavioral difficulties at 4 years old: Moderation by family risk characteristics. Developmental Psychology, 44, 155-168. http://dx.doi.org/10.1037/0012-1649.44.1.155

Edie, D. (2006). Towards a new child care policy. In Perspectives on Low-Income working Families. Washington. DC: The Urban Institute. Retrieved from http://www.urban.org/url.cfm?ID=311347

Fein, G. G., \& Fox, N. (1988). Infant day care: A special issue. Early Childhood Research Quarterly, 3(3), 227-234. http://dx.doi.org/10.1016/0885-2006(88)90002-6

Gartstein, M. A., Putnam, S. P., \& Rothbart, M. K. (2012). Etiology of preschool behavior problems: Contributions of temperament attributes in early childhood. Infant Mental Health Journal, 33, 197211. http://dx.doi.org/10.1002/imhj.21312

Geoffroy, M. C., Côté, S. M., Parent, S., \& Séquin, J. R. (2006). Daycare attendance, stress, and mental health. Canadian Journal of Psychiatry, 51, 607-615. Retrieved from http://ww1.cpa-apc.org:8080/publications/archives/cjp/2006/august/geoffroy-rp.asp

Jaffee, S. R., Van Hulle, C., \& Rodgers, J. L. (2011). Effects of non-maternal care in the first three years on children's academic skills and behavioral functioning in childhood and early adolescence: A sibling comparison study. Child Development, 82, 1076-1091. http://dx.doi.org/10.1111/j.1467-8624.2011.01611.x

Lamb, M. E. (1998). Nonparental child care: Context, quality, correlates. In W. Damon, I. E. Sigel, \& K. A. Renninger (Eds.), Handbook of child psychology: Vol. 4. Child psychology in practice (5th ed., pp. 73-134). New York: John Wiley \& Sons, Ltd.

Lekhal, R. (2012). Do type of childcare and age of entry predict behavior problems during early childhood? Results from a large Norwegian longitudinal study. International Journal of Behavioral Development, 36, 197-204. http://dx.doi.org/10.1177/0165025411431409

Maldonado-Carreño, C., \& Votruba-Drzal, E. (2011). Teacher-child relationships and the development of academic and behavioral skills during elementary school: A within- and between-child analysis. Child Development, 82, 601-616. http://dx.doi.org/10.1111/j.1467-8624.2010.01533.x

McCartney, K. (2004). Current research on child care effects. In R. E. Tremblay, R. G. Barr, \& R. DeV. Peters (Eds.), Encyclopedia on early childhood development (online) (pp. 1-5). Montreal, Quebec: Centre of Excellence for Early Childhood Development.

McCartney, K., Burchinal, M., Clarke-Stewart, A., Bub, K. L., Owen, M. T., Belsky, J., \& NICHD Early Child Care Research Network. (2010). Testing a series of causal propositions relating time in child care to children's externalizing behavior. Developmental Psychology, 46, 1-17. http://dx.doi.org/10.1037/a0017886

McCartney, K., Dearing, E., Taylor, B. A., \& Bub, K. L. (2007). Quality child care supports the achievement of low-income children: Direct and indirect pathways through caregiving and the home environment. Journal of Applied Developmental Psychology, 28, 411-426. http://dx.doi.org/10.1016/j.appdev.2007.06.010

Melhuish, E., Quinn, L., Hanna, K., Sylva, K., Siraj-Blatchford, I., \& Sammons, P., et al. (2006). The Effective Pre-school Provision in Northern Ireland Project: Summary report. Belfast, Northern Ireland: Stranmillis University Press.

Morrisey, T. W. (2010). Sequence of child care type and child development: What role does peer exposure play? Early Childhood Research Quarterly, 25, 35-50. http://dx.doi.org/10.1016/j.ecresq.2009.08.005

National Association of Child Care Resource and Referral Agencies. (2008). Center child care licensing requirements (September 2008): Minimum early childhood education (ECE) preservice qualifications and annual ongoing training hours for teachers and master teachers. Retrieved from http://www.naccrra.org/randd/data/TeacherTraining.php

NICHD Early Child Care Research Network. (1999). Child care and mother-child interaction in the first 3 years of life. Developmental Psychology, 35, 1399-1413. http://dx.doi.org/10.1037/0012-1649.35.6.1399

NICHD Early Child Care Research Network. (2000). Characteristics and quality of child care for toddlers and preschoolers. Applied Developmental Science, 4, 116-135. http://dx.doi.org/10.1207/S1532480XADS0403_2

NICHD Early Child Care Research Network (2001). Child care and family predictors of preschool attachment and $\begin{array}{lllll}\text { stability from } & \text { infancy. Developmental }\end{array}$ 
http://dx.doi.org/10.1037/0012-1649.37.6.847

NICHD Early Child Care Research Network. (2002). The interaction of child care and family risk in relation to child development at 24 and 36 months. Applied Developmental Science, 6, 144-156. http://dx.doi.org/10.1207/S1532480XADS0603_4

NICHD Early Child Care Research Network. (2003). Families matter - even for kids in child care. Journal of Developmental and Behavioral Pediatrics, 24, 58-62. http://dx.doi.org/10.1097/00004703-200302000-00011

NICHD Early Child Care Research Network. (2004). Type of child care and children's development at 54 months. Early Childhood Research Quarterly, 19, 203-230. http://dx.doi.org/10.1016/j.ecresq.2004.04.002

NICHD Early Child Care Research Network. (2005). Early child care and children's development in the primary grades: Follow-up results from the NICHD study of early child care. American Educational Research Journal, 42, 537-570. http://dx.doi.org/10.3102/00028312042003537

NICHD Early Child Care Research Network. (2006). Child-care effect sizes for the NICHD Study of Early Child

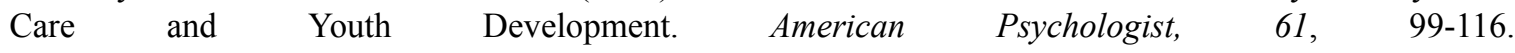
http://dx.doi.org/10.1037/0003-066X.61.2.99

Romano, E., Kohen, D., \& Findlay, L.C. (2010). Associations among child care, family, and behavior outcomes in a nation-wide sample of preschool-aged children. International Journal of Behavioral Development, 34, 427-440. http://dx.doi.org/10.1177/0165025409351657

Rosenthal, R., \& Vandell, D. L. (1996). Quality of care at school-aged child-care programs: Regulatable features, observed experiences, child perspectives, and parent perspectives. Child Development, 67, 2434-2445. http://dx.doi.org/10.2307/1131632

Sammons, P., Sylva, K., Melhuish, E., Siraj-Blatchford, I., Taggart, B., \& Elliot, K. (2003). Measuring the impact of pre-school on children's social behavioural progress over the pre-school period (EPPE Tech. Paper 8b). London: DfES/Institute of Education.

Sander, L.W., Julia, H.L., Stechler, G., \& Burns, P. (1972). Continuous 24-hour interactional monitoring in infants reared in two caretaking environments. Psychosomatic Medicine, 34, 270-282.

Statistics Canada. (2003). Cycle 4 (2000-01) user's guide. Ottawa, Ontario: Statistics Canada.

Statistics Canada. (2008). Cycle 7 (2006-07) user's guide. Ottawa, Ontario: Statistics Canada.

Statistics Canada and Human Resources Development Canada. (1995). National Longitudinal Survey of Children and Youth: Overview of survey instruments for 1994-1995 data collection cycle 1. Ottawa, ON, Statistics Canada and Human Resources Development Canada.

Stein, A., Malmberg, L.-E., Leach, P., Barnes, J., Sylva, K., \& the FCCC team. (2012). The influence of different forms of early childcare on children's emotional and behavioural development at school entry. Child: Care, Health and Development. http://dx.doi.org/10.1111/j.1365-2214.2012.01421.x

Strayhorn, J. M., \& Weidman, C. S. (1988). A Parent Practices Scale and its relation to parent and child mental health. Journal of the American Academy of Child and Adolescent Psychiatry, 27, 613-618. http://dx.doi.org/10.1097/00004583-198809000-00016

Tremblay, R. E., Nagin, D. S., Seguin, J. R., Zoccolillo, M., Zelazo, P. D., Boivin, M., et al. (2004). Physical aggression during early childhood: Trajectories and predictors. Pediatrics, 114, 43-50. http://dx.doi.org/10.1542/peds.114.1.e43

Vandell, D. L. (2004). Early child care: The known and the unknown. Merrill-Palmer Quarterly, 50, 387- 414. http://dx.doi.org/10.1353/mpq.2004.0027

Vandell, D. L., Burchinal, M., Vandergrift, N., Belsky, J., Steinberg, L., \& NICHD Early Child Care Research Network. (2010). Do effects of early child care extend to age 15 years? Results from the NICHD study of early child care and youth development. Child Development, 81, 737-756. http://dx.doi.org/10.1111/j.1467-8624.2010.01431.x

Votruba-Drzal, E., Levine-Coley, R., Maldonado-Carreño, C., Li-Grining, C. P., \& Chase Lansdale, P. L. (2010). Child care and the development of behavior problems among economically disadvantaged children in middle childhood. Child Development, 81, 1460-1474. http://dx.doi.org/10.1111/j.1467-8624.2010.01485.x

Waldfogel, J. (2001). International policies toward parental leave and child care. The Future of Children/Center for the Future of Children, the David and Lucile Packard Foundation, 11, 98-111. 
http://dx.doi.org/10.2307/1602812

\section{Appendix}

\begin{tabular}{|c|c|c|c|c|c|c|c|c|c|c|c|c|}
\hline & 1 & 2 & 3 & 4 & 5 & 6 & 7 & 8 & 9 & 10 & 11 & 12 \\
\hline 1. Process quality & -- & & & & & & & & & & & \\
\hline 2. Structure quality & $-.14 * *$ & -- & & & & & & & & & & \\
\hline 3. Regulated care & .01 & $.17 * *$ & -- & & & & & & & & & \\
\hline 4. Center-based care & .04 & -.03 & $.60^{* *}$ & -- & & & & & & & & \\
\hline 5. Hours in care & .07 & -.03 & $.17 * *$ & $.14 * *$ & -- & & & & & & & \\
\hline 6. Household income & -.03 & .03 & .08 & .02 & .07 & -- & & & & & & \\
\hline 7. Intact family structure & .01 & -.04 & $.14 * *$ & .05 & .06 & $.29 * *$ & -- & & & & & \\
\hline 8. Female child & $-.13 *$ & .09 & .01 & .03 & -.05 & .05 & .07 & -- & & & & \\
\hline 9. Child temperament & $.11^{*}$ & -.09 & -.02 & -.03 & .05 & $.10^{*}$ & .10 & .00 & -- & & & \\
\hline 10. Hostile/neffective interactions & $.10^{*}$ & -.08 & -.04 & .09 & $.11^{*}$ & .07 & -.07 & $-.13 * *$ & $.30 * *$ & -- & & \\
\hline 11. Positive family interactions & $-.12 *$ & .02 & $-.11^{*}$ & .01 & $-.15^{* *}$ & .02 & $-.18^{* *}$ & -.03 & $-.13 * *$ & .06 & -- & \\
\hline 12. High family dysfunction & $-.13 * *$ & .05 & $-.10^{*}$ & $-.28 * *$ & -.10 & .04 & .00 & .07 & .06 & .05 & -.10 & -- \\
\hline
\end{tabular}

Note. ${ }^{*} p<.05 ; * * p<.01$

\section{Copyrights}

Copyright for this article is retained by the author(s), with first publication rights granted to the journal.

This is an open-access article distributed under the terms and conditions of the Creative Commons Attribution

license (http://creativecommons.org/licenses/by/3.0/). 